\title{
Guest Editors’ Introduction
}

\section{Special Issue on Digital Society and E-Technologies}

\author{
Tomayess Issa \\ School of Information Systems \\ Curtin University \\ Australia \\ Tomayess.Issa@cbs.curtin.edu.au \\ Pedro Isaias \\ Universidade Aberta (Portuguese Open University) \\ Lisbon, Portugal \\ pisaias@univ-ab.pt \\ Piet Kommers \\ University of Twente \\ The Netherlands \\ P.A.M.Kommers@utwente.nl
}

It is evident that E-Technology (i.e. The Internet, social media... etc.) play a significant role in maintaining and supporting our digital society in various sectors from business, education, health and government and others. E-Technologies are now available worldwide for numerous numbers of universal users to increase collaboration, communication, interaction, creativity, critical thinking and problem solving in developing and developed countries. It is anticipated, and there is evidence gathering that E-technologies use will increase work performance, productivity, innovation, workers' satisfaction, reduce cost and maintenance. On the other hand, adopting e-technologies will bring various negative aspects in relation to security, privacy, legal aspects and users' frustration, as majorities of these e-technologies are still neglecting important aspects, i.e. Human Computer Interaction and usability. It is anticipated that these aspects will assist to improve the system functionality, which can be used efficiently, effectively and satisfactorily by universal users, including people with disability.

This special issue aims to investigate and assess the importance of e-technologies implemented in our digital society and deliberate and discuss the weakness and strengths behind their adoption. This special issue resulted from the selection of the best papers from the Internet Technologies and Society 2012 conference (www.its-conf.org), organized by the International Association for Development of the Information Society (IADIS). These best papers have been extended and reviewed for this special issue. A blind review process has been adopted to review and assess these articles for this special issue.

The special issue is comprised of four papers:

Article 1: "A Study of Service Quality and Important Features of Property Websites in Indonesia" from Nizar et al. aims to analyze the service quality of property websites in Indonesia to assist website owners in evaluating their website, and the SERVQUAL method which measures the gap between visitor's expectation and satisfaction. A questionnaire was employed in this study, and 101 valid respondents completed the survey. The results showed that respondents considered the service quality of the websites to still be under their expectations in all SERVQUAL dimensions which include reliability, assurance, tangibility, empathy, and responsiveness. 
Article 2: "A Framework to evaluate Information Quality in Public Administration Websites" from Geraci et al. aims to present a framework to assess the capacity of public administration bodies (PA), to offer a good quality of information and service on their web portals. This framework provides an on-going monitoring process of the PA websites that can contribute to the improvement of their overall quality. Finally, this framework can be benefited local governments in other countries, including Italy.

Article 3: "Maintaining Information Security in the new Technological Scenario" from Malandrin et al. aims to identify the technology challenges use in information security. Based on the literature review checkpoints are created and inserted into the basic processes of Information Security Management Systems, to develop and design a framework for security policy definition and risk management. This framework aims to assist security practitioners to manage the security challenges created by a disruptive technological scenario.

Article 4: "Business Processes as Social Entities - A Use Case Driven Approach" from Werth et al aims to identify the potentials of social media in the Business Process Management (BPM). Furthermore, authors aim to push forward innovative concepts and to form a basis to develop more IS artifacts in the context of social media enhanced business processes. The paper closes with a conclusion and an outlook on future research. The results show that particularly in the phases of "Business Process Design" and "Business Process Controlling" so far there exist unexploited potentials.

In conclusion, this special issue aims to present that e-technologies play a major role in various sectors, including property and businesses, to improve productivity, performance and proficiency. However, businesses and individuals must consider the drawbacks behind this technology, including security. Finally, this special issue will be beneficial for public and private organizations, IS developers and researchers, education managers, Professionals related to the Information Society and ICT and education sectors.

\section{About Guest Editors}

Dr. Tomayess Issa is a Senior Lecturer at Curtin University, Australia. Completed her doctoral research in Web development and Human Factors, and she is a member of an international conference program committee. Currently conduct research locally and globally in information systems, $\mathrm{HCl}$, Usability, Internet, Sustainability and Green IT, social network, teaching and learning.

Pedro Isaías is an associate professor at the Universidade Aberta (Portuguese Open University) in Lisbon, Portugal, responsible for several courses and director of the master degree program in Electronic Commerce and Internet since its start in 2003. He holds a PhD in Information Management (in the speciality of information and decision systems) from the New University of Lisbon. Author of several books, book chapters, papers and research reports, all in the information systems area, he has headed several conferences and workshops within the mentioned area. He has also been responsible for the scientific coordination of several EU funded research projects. He is also member of the editorial board of several journals and program committee member of several conferences and workshops. At the moment he conducts research activity related to Information Systems in general, E-Learning, E-Commerce and WWW related areas.

Piet Kommers is Associate professor at the University of Twente, The Netherlands. His specialty is social media for communication and organisation. As conference co-chair of the IADIS multi-conference he initiated the conferences of Web-Based Communities \& Social Media, E-Society, Mobile Learning and International Higher Education. He is professor at the UNESCO Institute for Eastern European Studies in Educational Technology and he is adjunct professor at Curtin University in Perth, Australia. 